\title{
A Framework for Evidence Based Visual Style Development for Serious Games
}

\author{
Tim McLaughlin \\ Department of Visualization \\ Texas A\&M University \\ College Station, Texas USA \\ timm@viz.tamu.edu
}

\author{
Dennie Smith \\ Department of Teaching \\ Learning \& Culture \\ Texas A\&M University \\ College Station, Texas USA \\ denniesmith@tamu.edu
}

\author{
Irving A. Brown \\ Department of Teaching \\ Learning \& Culture \\ Texas A\&M University \\ College Station, Texas USA \\ iabrown@tamu.edu
}

\begin{abstract}
In this paper, we describe a framework for connecting computer graphics techniques and visual style in video game design with targeted learning outcomes for students. The relationship is organized on a table depicting Bloom's taxonomy of the cognitive domain and categories of computer graphics imagery from simplified to realistic. This framework is presented as a useful way to economize design development efforts and incorporate visual development in addition to player immersion as an indicator of expected effectiveness for serious games.
\end{abstract}

\section{Categories and Subject Descriptors}

K.3.1 [Computer Uses in Education]: Computer-assisted instruction; I.5.1 [Multimedia Information Systems]: Animations-Evaluation/Methodology

\section{Keywords}

computer graphics, serious games, learning theory, game development, animation, cognition

\section{INTRODUCTION}

Serious games for education are teaching tools developed with the specific goal of assisting learning. Like traditional teaching material, games can be modified to serve the delivery of a variety of subject matters and a range of learning objectives. A tool's efficiency is measured by the amount of effort required to employ it relative to the progress gained by its employment. This paper provides a framework for relating the effectiveness of serious games to the sophistication of computer graphics techniques used to create visuals, independent of measures of player immersion.

The field of serious games remains at a stage where the number of educators with an interest in delivering learning opportunities via games outstrips the number of skilled

Permission to make digital or hard copies of all or part of this work for personal or classroom use is granted without fee provided that copies are not made or distributed for profit or commercial advantage and that copies bear this notice and the full citation on the first page. To copy otherwise, to republish, to post on servers or to redistribute to lists, requires prior specific permission and/or a fee.

FDG'10 June 19-21, Monterey, CA, USA

Copyright 2010 ACM 978-1-60558-937-4 ...\$10.00. serious game designers and developers. Exploration into serious game development often begins with the example of a successful entertainment oriented game as a touchstone for both game play and visual design. The logic is rational and straightforward: if developers achieve levels of engagement among students playing a serious game similar to the engagement among players of popular entertainment oriented games then success in achieving learning outcomes is more likely to occur. Most measures of the impact of games on learning point to a positive influence, with variability based upon the type of learning involved. A recent analysis of six games developed specifically for STEM (Science, Technology, Engineering, and Math) learning demonstrated a $7 \%-40 \%$ increase in subject matter competency among players over their counterparts participating in a traditional lecture program covering the same material [11].As this example, and others described later in the paper show, the case in favor of developing serious games for teaching and learning is clear. An element that is missing, one that would prove highly informative for educators and game designer/developers alike, is evidential analysis of the specific visual elements of serious games that contribute to learning.

Games may be defined by game-play structure and level of graphics sophistication. Most scholarly discourse regarding the effectiveness of games as teaching tools focuses on game structure and its impact on player immersion. Our work considers the effectiveness of differing modes of visual representation. We focus on creating a framework for pairing computer graphics techniques used in game development with learning outcomes expected for a serious game. For example, realism in computer generated imagery has been shown to contribute significantly to "same/different" discriminations [2]. Accurate motion and dimensional representation is essential and superior to $2 \mathrm{D}$ graphics for training pilots to fly and land aircraft using visual flight rules in simulators. However, if a game is being designed to teach physical geography we do not know if soft shadows and motion blur will increase the learning effectiveness of the game. Different methods of visual representation (photographic, shaded drawing, line drawing, and abstracted/cartoon) have been demonstrated to impact the speed at which a viewer can identify objects, and importantly, the most effective form of representation varies depending upon the complexity of the forms represented [18].

We expect this work will be of interest to educators and game developers alike. The optimal broader outcome of this work is a trustworthy process for determining the visual de- 
velopment needs for a game independent of the question of game structure and semi-independent of level of immersion. When the table is sufficiently populated with data, the learning objectives required for the game to be considered a successful teaching tool can be reliably matched with the visual development requirements; often the most costly and resource intensive aspect of game development. Educators and game developers alike should be able to understand with a relatively high degree of confidence that reducing the visual style requirements from photo-real character modeling to more simplified forms may effect students' ability to recall the Gettysburg address but will not impact their ability to contextualize the impact of the speech within the themes of the American Civil War.

\section{RELATED WORK}

\subsection{Games for Teaching and Learning}

Games for teaching and learning, often called serious games, differ from games for entertainment by the rationale for their design. Serious games are designed to have an explicit and carefully thought-out educational purpose [1]. The reason we use games for education is to exploit their appeal. The desire to use games for learning is based upon the assumption that students learn more when they are highly engaged. Koster [9] extends an equivalency between engagement, fun, and learning, "Fun from games arises out of mastery. It arises out of comprehension. It is the act of solving puzzles that makes games fun. In other words, with games, learning is the drug." Educators witness the zeal with which students apply themselves to video games and desire to garner such affinity for learning formal subjects. Video games have been used to teach history [19], chemistry [15], and computer science [20] among many other examples. Video games are even used to teach students how to create interactive stories for video games [4].

The key question is not whether students will apply themselves to video games built as teaching tools, but are the games as effective, or more so, than traditional book, lecture, and lab instruction. Most academic inquiry into the effectiveness of games for learning has focused on player immersion as the determining factor [6][21]. Accordingly, game development efforts have focused on designing games that are structurally and visually similar to successful entertainment oriented games. Ketelhut, et al. [7] employed a multi-user, avatar based, 3D environment and found that the capacity for inquiry and motivation was heightened in K-12 science students, but competency over subject matter did not increase significantly over the control group in two out of three trials. Kickmeier-Rust, et al., [8] proposed that, for teaching and learning purposes, 3D immersive games are intrinsically superior to $2 \mathrm{D}$ games because the latter fail to hold a players attention for extended periods of time. Kickmeier-Rust, et al., contribute to the ELEKTRA Project, an interdisciplinary European-based game development effort dedicated to creating a methodology for developing an immersive game to teach standardized physics lessons.

Evidence points to the effectiveness of serious games being a more complex issue than can be addressed by focusing solely on the goal of player immersion. Where does visual imagery fit into the equation? Advancements in computer graphics are leading to the achievement highly believable immersive synthetic environments. Current logic holds that visual sophistication equates to player immersion and if immersion is the key to learning then visual development efforts for serious games must move in step with the high end of CGI.

VisualComplexity $=$ PlayerImmersion $=$ Learning

This can be a high cost pursuit that the typical budget for educational games cannot accommodate. Fortunately, experience in the use of computer graphics imagery (CGI) in movies and games for entertainment provide evidence that effectiveness can be achieved through a range of levels of visual sophistication. The key to making the correct visual development decisions lies in understanding the relationship between computer graphics techniques, the resulting visual design style, and the effect of the visual design style on specific learning outcomes.

\subsection{Taxonomy of CG Techniques}

After publication and dissemination of Ivan Sutherland's Sketch-pad: A Man-Machine Graphical Communication System [22] scholarship into computer graphics began to extend beyond the confines of a small number of military and information processing research centers. Today's advancements in computer graphics techniques include contributions from mathematicians, scientists, artists, and educators representing corporate and government funded research labs, academic institutions, and private industry. While innovations in computer graphics continue to include diverse applications the greatest impact on both interest and development over the past twenty years has either arisen directly from, or been heavily influenced by, the use of computer graphics imagery (CGI) in entertainment media. A primary interest of entertainment media is presenting characters and environments. Thus, evolution of CGI has occurred in three primary areas: modeling (Form), animation (Motion), and rendering (Surfaces \& Light). In an effort to categorize the relationship between computer graphics techniques and the style of imagery to which they apply McLaughlin[12] developed a taxonomy related to the production of digital characters. We have adopted the structure of the taxonomy with a few modifications.

\section{Simplified}

Form: Objects and ideas represented as symbolic forms. Level of detail is low.

Motion: Non-articulation of figures. Motion fidelity is low.

Surfaces 8 Light: Flat shading; vector graphics.

\section{Stylized}

Form: Identifiable objects with un-realistic proportions or juxtapositions of parts. Level of detail can range from low to high.

Motion: Articulation and deformation of figures present. Expressive actions are magnified. Motion fidelity varies according to expressive requirements.

Surfaces 86 Light: Shading of curved surfaces, transparency, texture mapping.

\section{Realistic}


Form: Photo-accurate modeling of familiar objects. Level of detail is high.

Motion: Coordinated systems defining both articulation and deformation such as from performance capture and physically based simulation. Motion fidelity is high.

Surfaces $\&$ Light: Photo-realistic shadow casting, reflections, caustics, light scattering, radiosity.

McLaughlin's framework is specific to digital characters but can be extended to encompass other uses of CGI. Visual design styles are categorized as being Primitive, Abstract, or Naturalistic, with each encompassing a non-unique set of computer graphics techniques most likely to be used to create imagery in that visual style. The term Primitive can be considered pejorative, indicating something less refined so we offer Simplified in its place. We have also substituted the original terms Abstracted with Stylized, and Naturalistic with Realistic. It is our opinion that the words Abstract and Naturalistic have a variety of interpretations, particularly in the realm of discussing imagery, and may be more confusing than Stylized and Realistic.

Precise classification using this taxonomy can be tricky. For example, a dragon created as a digital creature can be modeled, animated, surfaced, and lit so as to match seamlessly in a photographed environment and live actors. Is the dragon realistic or abstracted? For our purposes we would classify a dragon as being stylized in Form, and Motion, because it is based upon an amalgamation of known creatures, but potentially realistic in Surfaces \& Light. The film Finding Nemo [2003] features stylized digital characters in form and motion, however many of the effects such as water, explosions, and even feathers could be considered realistic. The game Borderlands [2007] features fairly idealistic, but plausibly realistic forms; however, the character motion is stylized and surfacing is graphically stylized.

\subsection{Effectiveness of CG in Movies}

With the release of Jurassic Park in 1993 computer generated Forms, Motion, and Surfaces \& Light reached a level of visual sophistication that made the ability to distinguish synthetic from real very difficult. Viewers accepted the notion that dinosaurs could inhabit the same world as human actors. With the proper level of technical and artistic expertise computer graphics could visually recreate reality, not just cartoon characters and shiny objects. The Curious Case of Benjamin Button [2008] and Avatar [2009] have extended the range of use of CGI to include realism in form, motion, materials and the physics of light in the depiction of humans and synthetic worlds. Despite storylines and character designs that are obviously fictitious, the visual imagery is believable to a degree that transcends the viewers desire to distinguish between abstraction and reality [16] [17].

However, as seen in Figure 1, achievement of viewer immersion in a synthetic world through realism in computer graphics imagery is not an automatic indicator of success.

Movies such as Toy Story [1995], and Shrek [2001] have presented highly stylized versions of characters, objects, and environments yet been highly successful in appealing to viewers as measured by box office figures. Films that mix realistic visual elements with simplified or stylized elements have sometimes achieved success (300 [2006]) and sometimes failed (Speed Racer [2008]). Figure 1 graphs the success, or

\begin{tabular}{|c|c|c|c|c|c|c|c|c|c|c|}
\hline & \multicolumn{3}{|c|}{ Form } & \multicolumn{3}{|c|}{ Motion } & \multicolumn{3}{|c|}{$\begin{array}{l}\text { Surfaces } \\
\text { \& Light }\end{array}$} & \multirow{2}{*}{ 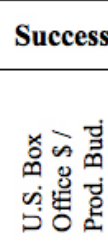 } \\
\hline & 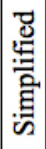 & 总 & 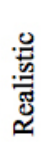 & 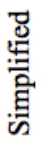 & $\frac{\text { D. }}{\text { 总 }}$ & 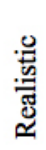 & 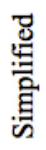 & 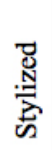 & 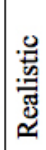 & \\
\hline Tron & & & - & & & - & & $\bullet$ & & 1.94 \\
\hline $\begin{array}{c}\text { Jurassic } \\
\text { Park }\end{array}$ & & & $\bullet$ & & & $\bullet$ & & & $\bullet$ & 5.55 \\
\hline Toy Story & & $\bullet$ & & & $\bullet$ & & & $\bullet$ & & 6.37 \\
\hline $\begin{array}{l}\text { The Tale of } \\
\text { Despereaux }\end{array}$ & & • & & & - & & & & • & 0.85 \\
\hline 300 & & & $\bullet$ & & & $\bullet$ & & $\bullet$ & & 4.77 \\
\hline Speed Racer & & & - & & & $\bullet$ & & $\bullet$ & & 0.37 \\
\hline
\end{tabular}

Figure 1: Relating Visual Style of CG Elements in Movies to Effectiveness (Box Office / Production Cost)

effectiveness, of several films relative to the design style of the computer graphics imagery seen in them.

The success of films listed in Figure 1 is measured by dividing the U.S. domestic box office gross by the estimated production cost (www.imdb.com; www.boxofficemojo.com). This is a dubious measure due to the number of issues that contribute to a film's box office success, and the difficulty of separating a film's computer graphics production costs from other costs such as live action production, talent, marketing, etc.

The role of $\mathrm{CG}$ visuals in filmmaking is to meet the director's expectations. Thus, evidence of the effectiveness of computer graphics imagery in movies is determined by the director's satisfaction, and indirectly from movie ticket sales. Developers of imagery for movies are faced with the direct challenge of determining the most efficient use of computer graphics techniques to meet the director's visual goals and can only indirectly measure the effectiveness of the visuals. Their counterparts in game development face similar challenges.

\subsection{Measures of Effectiveness for Video Games}

As with the use of visually sophisticated computer graphics in film production, realistic graphics in video games can be an indicator of success, but is not a guarantee. Figure 2 lists a selection of the most popular video games and assesses the computer graphics employed in them.

Estimating the number of video game players overall, or for a particular game, is difficult. The numbers used in Figure 2 for console games (Call of Duty: Modern Warfare 2, New Super Mario Bros. Wii, and Wii Sports Resort) are estimated by units sold (www.gamedaily.com). The numbers for PC and mobile games (Farmville, Second Life, and Solitaire) are determined by number of unique players in a given month [14].

Using the number of players to measure a game's effectiveness is contentious. The delivery mechanism for each game has an enormous impact on the number of players. Games that provide near effortless accessibility as a result 


\begin{tabular}{|c|c|c|c|c|c|c|c|c|c|c|}
\hline & \multicolumn{3}{|c|}{ Form } & \multicolumn{3}{|c|}{ Motion } & \multicolumn{3}{|c|}{$\begin{array}{l}\text { Surfaces } \\
\text { \& Light }\end{array}$} & \multirow{2}{*}{ 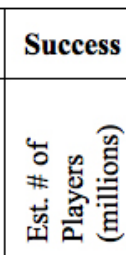 } \\
\hline & 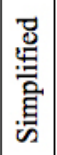 & 蛋 & 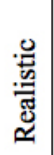 & 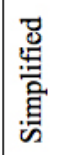 & 总 & 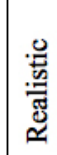 & 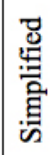 & 总 & 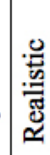 & \\
\hline $\begin{array}{c}\text { Call of } \\
\text { Duty: } \\
\text { Modern } \\
\text { Warfare 2 }\end{array}$ & & & • & & & • & & & • & 0.2 \\
\hline Farmville & & $\bullet$ & & • & & & • & & & 72.9 \\
\hline $\begin{array}{c}\text { New Super } \\
\text { Mario } \\
\text { Bros. Wii }\end{array}$ & & • & & $\bullet$ & & & • & & & 0.15 \\
\hline $\begin{array}{c}\text { Second } \\
\text { Life }\end{array}$ & & $\bullet$ & & & - & & & - & & 0.22 \\
\hline $\begin{array}{c}\text { Microsoft } \\
\text { Solitaire }\end{array}$ & $\bullet$ & & & • & & & • & & & 17 \\
\hline $\begin{array}{c}\text { Wii Sports } \\
\text { Resort }\end{array}$ & & $\bullet$ & & & • & & & • & & 0.15 \\
\hline $\begin{array}{l}\text { World of } \\
\text { Warcraft }\end{array}$ & & & $\bullet$ & & & $\bullet$ & & • & & 1.1 \\
\hline
\end{tabular}

Figure 2: Relating Visual Style in Entertainment Oriented Video Games to Effectiveness as Measured by Popularity

of bundling with a PC (Microsoft Solitaire) or coupling with social media (Farmville) have large player numbers as compared to games that require a prospective player to first purchase a game or subscription. Also, immersion in a game is not measured by counting the number of players, but by measuring the amount of time spent playing. Casual game players average around 31 minutes per game play session while players of non-casual games average a play session duration of 80 minutes, with World of Warcraft players spending nearly two hours per game session[13]. Thus, immersion does not measure a game's effectiveness as entertainment.

\subsection{Effective Serious Game Development}

Game developers interested in creating games for teaching and learning could become confused by the variety of inconclusive indicators of which design decisions will lead to effectiveness. This situation, and the desire for immersion, has led many developers of serious games to align their game designs with the structures and visual styles of entertainment oriented games with proven records of success in either attracting large numbers of players or producing extended periods of game-play. Concerned that the rush to pour educational content into the structures of entertainment games was resulting in games that ignore learning theories Gunter, et al. [5] offered a design paradigm for serious games based upon learning theories. Using Bloom's Taxonomy of the Cognitive Domain, Keller's ARCS Model, and Gagne's Events of Instruction, Gunter's RETAIN (Relevance Engagement Translation Assimilation Immersion Naturalization) structure seeks to provide a method for ensuring that a game's structural elements for entertainment reinforce its didactic purpose and vice-versa. While the $R E$ TAIN method maps the structure of game play to learning theories it does not include game development in terms of visual style and graphics presentation. To accomplish this task we will simplify the objectives of the RETAIN method and concentrate on Bloom's Taxonomy

In 1956 Benjamin Bloom, et. al., published Taxonomy of Educational Objectives: The Classification of Educational Goals. Handbook I: Cognitive Domain, offering a common language for classifying what educators expect students to learn [3]. A primary goal in offering the framework was to set a means of sharing test items intended to measure similar learning objectives, thus aiding in the preparation of standardized tests [10]. Since its first publication Bloom's Taxonomy, as it is commonly known, has been used as a basis for developing course material, for determining the congruence of courses in a curriculum, and as a means for setting broad educational goals at local, state, and national levels. As schools replace traditional textbook based learning with digital technology, including games, it is expected that increased emphasis will be placed on curricular and learning objective specification and alignment.

The taxonomy offered six categories, or levels, of understanding: Knowledge, Comprehension, Application, Analysis, Synthesis, and Evaluation. The categories range from simple to complex and from concrete to abstract [10]. The taxonomy assumes a hierarchy of learning with mastery of the more simple and concrete levels required before success can be achieved at the more complex and abstract levels. Desirable learner behavior within each domain can be described as follows:

1. Knowledge: remembering information

2. Comprehension: explaining the meaning of information

3. Application: using abstractions in concrete situations

4. Analysis: breaking down a whole into component parts

5. Synthesis: putting parts together to form a new and integrated whole

6. Evaluation: making judgments about the merits of ideas, materials, phenomena

Bloom's Taxonomy provides clear levels for classifying the skills of learners. Educators can fit each component of a body of knowledge into the framework to gain greater control over building skills or use the taxonomy as a guide for defining a progression of learning. Both are useful processes for designing serious games.

\section{PAIRING CGI WITH LEARNING OUT- COMES}

\subsection{Learning Level and Visual Style}

Learning outcomes and computer graphics each exist on a continuum ranging from simple to complex. While it would be straightforward to assume that the teaching and learning of complex subject matter requires the use sophisticated computer graphics the true situation is more nuanced. Some games requiring high levels of cognitive accomplishment, such as requiring the player to assimilate and use knowledge 
to create novel objects or situations, may be best served by simplified graphics.

A single game structure can be executed through a variety of visual styles, each requiring a different set of computer graphics techniques. Generally, imagery that is more realistic and complex requires a higher level of artistic and technical expertise and more computational power to be accomplished. We expect that the continued evolution of the field of computer graphics combined with growth and maturity of the workforce will contribute to a downward trend in the man-hour and infrastructure cost per game. In effect, the ability to produce highly complex and realistic visuals for games will be within reach of even modestly funded projects in the not too distant future. We do not expect, however, that the overall effectiveness of serious games on learning will rise as a consequence of greater realism.

We provide a framework and look for future work of our own and of others to provide a database establishing connections between visual design and learning outcomes. This framework will serve as a guide for subject area experts when considering the most appropriate form for a video game covering their material.

Currently, we must speculate about the way visuals influence learning. Generally, we do not know if a game developed using 2D Flash animation can be as effective in covering a specific kind of learning as the same game developed using 3D graphics with realistic lighting, motion, and models. If the goal is for players to spend more time playing the game then we may assume that the $3 \mathrm{D}$ visually sophisticated game will be more effective than the $2 \mathrm{D}$ game. However, as was discussed earlier, studies measuring player immersion have produced learning effectiveness results that vary based upon the level of cognition measured. For a serious game in which information retention is the learning goal we may safely assume that more time spent playing is likely to be a good thing. However, if the learning goal is application of knowledge or synthesis of information with existing knowledge do we know that more time spent playing is effective?

What if a learner's success rate in meeting learning objectives on increasingly sophisticated learning levels tracks inversely with the sophistication of computer graphics techniques used in serious games delivering the material? Could it be that simplified and stylized visuals in a game are more likely to assist a learner in assimilation and use of complex information, while realistic forms and motion contribute to identification and recall?

Figure 3 lists three primary areas of computer graphics as used in games: Form, Motion, and Materials \& Light. Each area ranges from simplified to realistic in visual complexity, with stylized as the middle step.

On the $y$-axis in Figure 3 are Bloom's six levels of cognition, or learning levels. For now, this table is devoid of information. It is only a framework. Our long-term goal is to begin filling in this table with evidence-based information. For example, it is possible that realistic motion has a large impact on player ability to apply principals of physical chemistry but forms, material, and light in the same game can be simplified without hindering learning. An answer to this question would make designing and developing a serious game covering physical chemistry a much more efficient process with predictable results.

\subsection{Current Work: Room 309}

\begin{tabular}{|c|c|c|c|c|c|c|c|c|c|}
\hline & \multicolumn{3}{|c|}{ Form } & \multicolumn{3}{|c|}{ Motion } & \multicolumn{3}{|c|}{$\begin{array}{c}\text { Materials } \\
\text { \& Light }\end{array}$} \\
\hline & 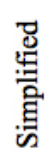 & 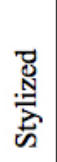 & 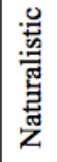 & 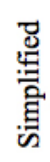 & 总 & 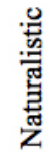 & 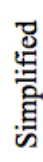 & 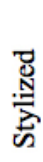 & 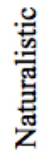 \\
\hline Knowledge & & & & & & & & & \\
\hline Comprehensio & & & & & & & & & \\
\hline Application & & & & & & & & & \\
\hline Analysis & & & & & & & & & \\
\hline Synthesis & & & & & & & & & \\
\hline Evaluation & & & & & & & & & \\
\hline
\end{tabular}

Figure 3: Matrix Aligning Visual Style with Learning Levels

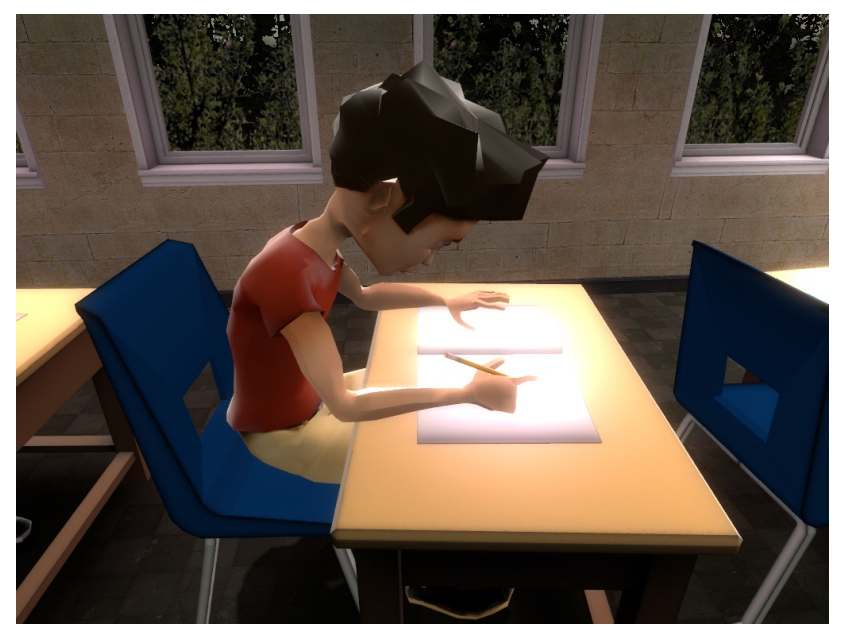

Figure 4: Screen capture from the pre-service teacher training game, Room 309, depicting stylized modeling, materials, and lighting.

To further this effort we are currently involved in the development of a serious game designed to provide pre-service secondary school teachers with exposure to common classroom situations, such as students copying work, arguing over seating assignments, and texting friends. This game, called Room 309, is being developed in two styles: one features characters and an environment stylized similar to cartoons (Figure 4). The other features simplified forms of the students and classroom, graphically similar to diagrams and signage, but in a 3D form (Figure 5).

The scenarios depicted are adapted from a series of video vignettes developed in the late 1980s and early 1990s to assist in developing pre-service teacher confidence in classroom decision making. Participants must (1) recognize student behavior that is inappropriate and (2) determine the most effective form of intervention for the given situation. Within Bloom's Taxonomy these two actions cover opportunities to demonstrate simple/concrete and complex/abstract learning, respectively. 


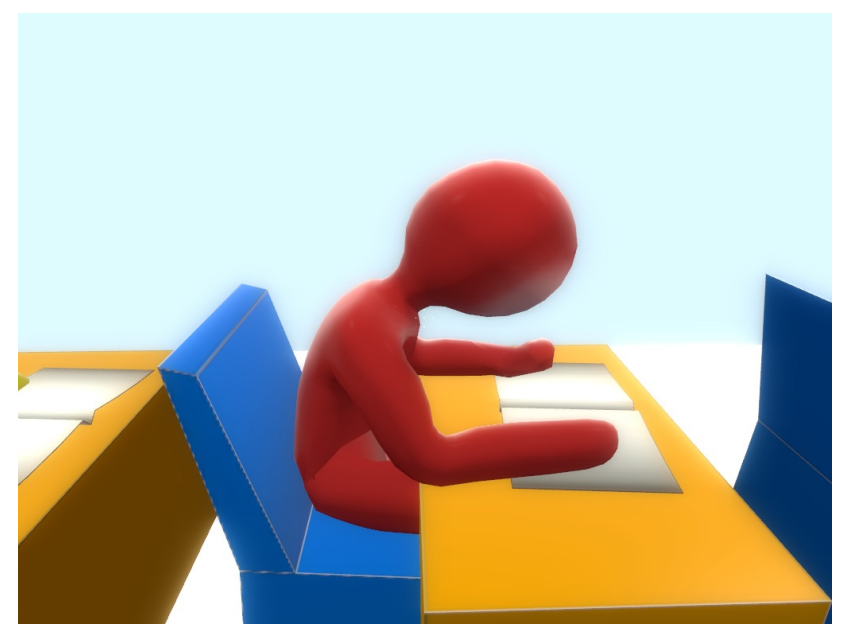

Figure 5: Screen capture from the pre-service teacher training game, Room 309, depicting simplified modeling, and materials with stylized lighting.

Our first step in assessing the validity of the video games as learning tools has been a series of comparative studies designed to determine if viewers see the same actions. To date, we have developed a scenario that compares a single classroom situation (recognition of cheating behavior) in video form with live actors in an actual classroom to a depiction of the same behavior in video game form in which the characters and classroom stylized as in Figure 4.

We have also developed four classroom scenarios (1) students cheating, (2) students arguing over a desk, (3) a student doing homework during a lecture, and (4) students texting one another during class, in both stylized and simplified forms. Studies are underway, using pre-service teachers as test subjects, to determine if recognition of events in the classroom is affected by the style of depiction of the characters and environment. In each scenario the layout of the room and animated actions of the characters is identical between the simplified and stylized forms of the games. We will follow studies of recognition with studies measuring whether or not there is a difference in the player's determination of appropriate intervention due to visual style presented in the game. A hypothesis is:

\section{VisualSimplicity $=$ HigherLevelLearning}

If players of both the stylized and simplified visual forms of the game Room 309 achieve similar graded scores on their ability to recognize and appropriately address classroom situations presented in the game we will have evidence that form is fairly inconsequential as a factor in developing situational analysis and evaluation skills. If, on the other hand, there is a marked difference in player ability to successfully identify and address situations in the simplified form of the game, for example, we may be able to determine that an abstracted level of character and environment realism contributes to the game's effectiveness as a teaching and learning tool.

\subsection{Future Work \& Broader Questions}

We recognize that game structure is likely the primary factor determining a serious game's effectiveness. Other fac- tors such as delivery platform and user input devices may outstrip visual design as factors determining effectiveness. However, we expect that the proposed framework will be useful to researchers and developers in future applications of various levels of graphic abstractions and representations of learning material. Once the framework has been proven to be a reasonable holder for evidence based visual design we would like to pursue answers to some of the following questions:

1. Does player age influence the effectiveness of visual design style?

2. Does the effectiveness of visual design style vary by gender or among cultures and/or ethnic groups?

3. What are the minimal levels of symbolic representation for form, motion, and material \& light at which a measurable effect in learning can be achieved at various levels of cognition?

4. In what areas of learning could simplified or stylized depictions create false training effects?

5. Is there an inverse relationship between image complexity and the hierarchy of learning?

6. Could real-time augmented reality tools (goggles) be employed to simply or stylize the elements in a traditional learning environment and thereby positively effect learning?

\section{CONCLUSION}

We have provided a framework for aligning the visual style of serious games with the expected learning outcomes for the games. Visual style in computer graphics is closely aligned with computer graphics techniques. While technical expertise and artistic skill is rising among the educators and game developers interested in producing serious games, and the cost of computing is trending lower, development costs remain a high hurdle for most projects. A long term goal of our framework is to assist in economical delivery of serious games.

Results from other studies on the effectiveness of games as learning tools indicate that creating serious games with player immersion as the single driving design goal is an imprecise method for targeting specific learning objectives. This framework is intended to provide a useful guide through which decisions about visual style development such as level of detail in forms, fidelity of motion, and accuracy of lighting effects, can be made with confidence that the game's capacity to meet its teaching and learning objectives can be met.

This model has evolved through analysis of the use of computer graphics in movies and games for entertainment. We use the terms Simplified, Stylized, and Realistic as classifiers of computer graphics techniques to assist in aligning visual style with effectiveness. For serious games, effectiveness varies based upon the level of cognitive learning desired. Our framework aligns visual design style with the six levels of cognition described in Bloom's original taxonomy. We are currently testing this framework through development of a serious game in two visual styles while maintaining the same game structure. We hope to provide evidence based data for our framework and that our work will inspire others to do the same. 


\section{ACKNOWLEDGMENTS}

Our thanks to Nathan Bajandas, Douglas Bell, Benjamin Bertka, Michelle Simms, and Dr. Vinod Srinivasan for their development efforts in serious gaming and ideas contributing to this paper. Funding for this work was provided by the office of the Vice President for Research at Texas A\&M University, College Station, Texas.

\section{REFERENCES}

[1] C. C. Abt. Serious Games. Viking Press, 1970.

[2] W. Barfield, J. Sandford, and J. Foley. The mental rotation and perceived realism of computer-generated three-dimensional images. International Journal of Man-Machine Studies, 29:669-684, 1988.

[3] B. Bloom and D. R. Krathwohl. Taxonomy of educational objectives: The classification of educational goals, by a committee of college and university examiners. Handbook 1: Cognitive domain. Longmans, New York, 1956.

[4] M. Carbonaro, M. Cutumisu, H. Duff, S. Gillis, C. Onuczko, J. Siegel, J. Schaeffer, A. Schumacher, D. Szafron, and K. Waugh. Interactive story authoring: A viable form of creative expression for the classroom. Comput. Educ., 51(2):687-707, 2008.

[5] G. A. Gunter, R. F. Kenny, and E. H. Vick. A case for a formal design paradigm for serious games. The Journal of the International Digital Media and Arts Association, 3(1):93-105, 2006.

[6] R. T. Hays. The Effectiveness of Instructional Games: A Literature Review and Discussion, Technical Report 2005-004. Naval Air Warfare Center Training Systems Division, 2005.

[7] D. J. Ketelhut. The impact of student self-efficacy on scientific inquiry skills: An exploratory investigation in river city, a multi-user virtual environment. Journal of Science Education and Technology, 16(1):99-111, 2007.

[8] M. D. Kickmeier-Rust, N. Peirce, O. Conlan, D. Schwarz, D. Verpoorten, and D. Albert. Immersive digital games: the interfaces for next-generation e-learning? In UAHCI'07: Proceedings of the 4th international conference on Universal access in human-computer interaction, pages 647-656, Berlin, Heidelberg, 2007. Springer-Verlag.

[9] R. Koster and W. Wright. A Theory of Fun for Game Design. Paraglyph Press, 2004.

[10] D. R. Krathwohl. A revision of bloom's taxonomy: An overview. Theory into Practice, 41(4):212-2182, 2002.

[11] M. J. Mayo. Video games: a route to large-scale stem education? Science, 323(5910):79-82, 2009.

[12] T. McLaughlin. Taxonomy of digital creatures: interpreting character designs as computer graphics techniques: Copyright restrictions prevent acm from providing the full text for this work. In SIGGRAPH '05: ACM SIGGRAPH 2005 Courses, page 1, New York, NY, USA, 2005. ACM.

[13] G. McMillan and B. Raczka. Insights on casual games: Analysis $f$ casual games for the $P C$. The Nielsen Company, 2009.

[14] G. McMillan and B. Raczka. The state of the video gamer: $P C$ game and video game console usage, fourth quarter 2008. The Nielsen Company, 2009.
[15] C. Morales, K. Martínez-Hernández, G. Weaver, R. Pedela, K. Maicher, E. Elkin, D. Danforth, and N. Nattam. Immersive chemistry video game. In SIGGRAPH '06: ACM SIGGRAPH 2006 Educators program, page 50, New York, NY, USA, 2006. ACM.

[16] J. Piazza. Audiences experience ÔavatarÕ blues. http://www.cnn.com/2010/SHOWBIZ/Movies/ 01/11/avatar.movie.blues/index.html, (Retrieved February 3, 2010), 2010.

[17] L. D. Rosenblum. Sensory superpowers: exploring our hidden perceptual skills. http://www.psychologytoday.com/ blog/sensory-superpowers/ 201001/i-want-hold-your-zombie-hand, (Retrieved February 3, 2010), 2010.

[18] T. A. Ryan and C. B. Schwartz. Speed of perception as a function of mode of presentation. American Journal of Psychology, 69:60-69, 1956.

[19] K. Squire and S. Barab. Replaying history: engaging urban underserved students in learning world history through computer simulation games. In ICLS '04: Proceedings of the 6th international conference on Learning sciences, pages 505-512. International Society of the Learning Sciences, 2004.

[20] K. Sung. Finding the fun in computer science education. Commun. ACM, 52(12):74-78, 2009.

[21] T. Susi, M. Johannesson, and P. Backlund. Serious games - an overview. Technical Report HS- IKI -TR-07-001, 2007.

[22] I. E. Sutherland. Sketchpad: A man-machine graphical communication system. In AFIPS Conference Proceedings, pages 323-328, 1963. 